\title{
SORTILÉGIO - ESTÉTICA E SUBJETIVAÇÃO DO SUJEITO NEGRO EM ABDIAS NASCIMENTO
}

\author{
LOPES FILHO, A. ${ }^{\text {; }}$ SILVA, M. L. ${ }^{2}$. \\ PALAVRAS ChAVE: Movimento Negro. Subjetivação. Estética. Abdias do Nascimento. Sortilégio.
}

\begin{abstract}
RESUMO
Este artigo é constituído de um recorte temático a partir dos estudos junto ao projeto de pesquisa intitulado "Biopolítica, educação e (des)construção do sujeito negro no Brasil pós-abolição (1888-1945)", desenvolvido no âmbito do Programa de Pós-graduação em Educação (mestrado e doutorado) da Universidade de Santa Cruz do Sul e coordenado pelo professor Dr. Mozart Linhares da Silva. 0 objetivo geral que norteou o projeto e, posteriormente, a construção deste trabalho, visa identificar a proposição de uma estética negra forjada a partir da década de $60 \mathrm{com}$ a dramaturgia presente no "Teatro Experimental Negro" (TEN) de Abdias do Nascimento, homem negro, filósofo e um dos principais expoentes culturais e políticos do Movimento Negro. Propõe-se pensar a arte, no caso a dramaturgia do TEN, como um dispositivo implicado nos processos de subjetivação, sobretudo em seus "efeitos" nas estratégias de resistência dos sujeitos negros. Problematiza-se, nesse sentido, o quanto o teatro de Abdias influenciou o desejo e a estética da negritude no Brasil, uma das pautas da militância da época, e em que medida a arte deu conta de servir de lugar de sustentação desses discursos. Para tanto, tomamos como corpus analítico da pesquisa a obra dramatúrgica de Abdias, "Sortilégio - Mistério Negro", de 1951.
\end{abstract}

\section{SORTILÉGIO - AESTHETICS AND SUBJECTIFICATION OF THE BLACK SUBJECT IN ABDIAS DO NASCIMENTO}

KEYWORDS: Black Movement. Subjectivation. Aesthetics. Abdias do Nascimento. Sortilégio.

\begin{abstract}
This article is made up from a thematic clipping of the research project titled "Biopolitics, education and (de) construction of the black subject in post-abolition Brazil (1888-1945)", developed under the Postgraduate Program in Education doctorate) at the University of Santa Cruz do Sul and coordinated by Professor Dr. Mozart Linhares da Silva. The general objective that guided the project and later the construction of this work, aims to identify the proposal of a black aesthetic forged from the 60s with the dramaturgy present in the "Black Experimental Theater" (TEN) of Abdias do Nascimento, a black man, philosopher and one of the main cultural and political exponents of the Black Movement. It is proposed to think art, in this case the dramaturgy of the TEN, as a device implicated in the processes of subjectivation, especially in its "effects" in the strategies of resistance of the black subjects. It is questioned in this aspect on how much the theater of Abdias influenced the desire and aesthetics of blackness in Brazil, one of the patterns of militancy of the time, and the extent to which art has served as a place to sustain these speeches. To do so, we take as analytical corpus of the research Abdias' dramaturgical work, "Sortilégio Mistério Negro", of 1951.
\end{abstract}

\footnotetext{
${ }_{1}^{1}$ Acadêmico do curso de Psicologia pela Universidade de Santa Cruz do Sul.

2 Docente do Departamento de História e Geografia e pesquisador no PPGEDU da Universidade de Santa Cruz do Sul.
} 


\section{INTRODUÇÃO}

Nietzsche considerava a experiência estética como um bom ponto de partida para a investigação da cultura; Foucault, em seu último projeto, articulou conceitos importantes a partir da antiguidade greco-romana de modo a pensar a estética da existência e a produção de si mesmo e da vida como obra de arte. Tomando como ponto de partida essas duas assertivas, propomos, neste trabalho, analisar a produção de subjetividades e a construção de uma proposta estética do Movimento Negro brasileiro entre meados do fim do Estado Novo e a ditadura militar (1945-1964) a partir do Teatro Experimental do Negro (TEN), movimento de resistência fundado por Abdias do Nascimento. Problematizamos, nesse sentido, a comunicação estabelecida na produção artística de Nascimento em Sortilégio - Mistério Negro, peça de teatro escrita entre 1950 e 1951. Tal obra, como característica do TEN, tratou de inaugurar no Brasil uma arte dramatúrgica negra, pensada e desenvolvida no sentido de construir um manifesto teatral sobre o qual o ator e a atriz negros pudessem dar vida à personagens e dramas que narrassem os conflitos étnico-raciais vivenciados pela população negra num país cujo teatro, por décadas, tratou de representá-los grotesca e caricatamente.

A proposta de Abdias, que extrapolou os palcos para tornar-se também um vértice de formação profissional e estudos da cultura negra, contribuiu também na construção de uma proposta estética do movimento. Esta proposta, em consonância com o movimento francês, empunhou a bandeira da Negritude, conceito dinâmico e multifacetado que traduz, dentre outras coisas, o ato de reconhecer-se sujeito negro implicado com o movimento (DOMINGUES, 2005). A análise de Sortilégio - Mistério Negro possibilita identificar o compromisso de Nascimento com a proposta da Negritude por via da reconstrução histórica e do retorno à matriz afro. Em suas palavras, faziase necessário não a acomodação cultural, mas a "reinvenção de um caminho afro-brasileiro de vida" (NASCIMENTO, 1980, p. 262). Este artigo apresenta uma breve contextualização do Movimento Negro no Brasil república, localizando o trabalho do TEN e de Nascimento na cronologia histórica das discussões e lutas identitárias do movimento, seguido de outra igualmente breve contextualização da proposta do Teatro Experimental do Negro. $\mathrm{A}$ seguir, apresentamos o constructo utilizado; um resumo da obra Sortilégio - Mistério Negro, de 1951; características do processo de análise e algumas considerações.

\section{NASCIMENTO NO CONTEXTO DO MOVIMENTO NEGRO NO BRASIL REPÚBLICA}

Petrônio Domingues (2007) classifica o Movimento Negro no Brasil República em quatro fases: A primeira, compreendida entre a Primeira República e o Estado Novo (1889-1937); a segunda, do fim do Estado Novo à ditadura militar (1945-1964); a terceira fase, de 1978 à 2000, do início do processo de redemocratização à República Nova; e a última, dos anos 2000 em diante. A primeira fase, na Primeira República, tem início um ano após a abolição e traz consigo um quadro de marginalização extrema. Clubes, grêmios e associações são fundadas por libertos, ex-escravos e seus descendentes. Um dos primeiros registros data de 1902, com o Club 13 de Maio dos Homens Pretos, em São Paulo. Contudo, sabe-se que já em 1889 Porto Alegre contava com os primeiros movimentos organizados. Nesse período surge também a denominada imprensa negra, destinada a veicular questionamentos acerca das condições do homem negro na sociedade brasileira. Domingues (2007, p. 105), aponta que esses jornais "enfocavam as mais diversas mazelas que afetavam a população negra no âmbito do trabalho, da habitação, da educação e da saúde, tornando-se uma tribuna privilegiada para se pensar em soluções concretas para o problema do racismo na sociedade brasileira." 
Os anos de ditadura "Varguista" silenciaram significativamente os movimentos sociais. Com o fim do Estado Novo, o Movimento Negro organizado retorna com força e novas demandas, configurando a segunda fase da luta organizada. A expansão do mercado trouxe consigo o aumento da competitividade, fazendo com que preconceitos e estereótipos perseguissem ainda mais a população negra (2007, p. 108). Em 1946 nasce a União dos Homens de Cor (UHC), ou Uagacê, fundada por João Cabral Alves, em Porto Alegre, e ainda na década de quarenta ganha sucursais em pelo menos dez Estados da Federação. Domingues (2007, p. 108) pontua que, em linhas gerais, a atuação da UHC era marcada pela "promoção de debates na imprensa local, publicação de jornais próprios, serviços de assistência jurídica e médica, aulas de alfabetização, ações de voluntariado e participação em campanhas eleitorais". Em 1950, representantes deste movimento apresentaram suas reivindicações em favor das "pessoas de cor", como denominavam o movimento neste período, ao então presidente Getúlio Vargas.

\subsection{0 teatro experimental do negro e Abdias no contexto do movimento}

Ainda durante a segunda fase do Movimento Negro, em 1944, um importante agrupamento é fundado no Rio de Janeiro: 0 Teatro Experimental do Negro (TEN), sob a liderança de Abdias do Nascimento, cuja proposta primordial era a de formar um grupo de atuadores composto somente por atores e atrizes negros. Tão logo o TEN é fundado e seu leque de articulação político-social é ampliado, oferecendo cursos de alfabetização, corte e costura e fundando o Instituto Nacional do Negro, além de propugnar a criação de uma legislação antidiscriminatória no país. Conforme Domingues (2007, p. 110), "O grupo foi um dos pioneiros a trazer para o país as propostas do movimento da negritude francesa, que, naquele instante, mobilizava a atenção do movimento negro internacional e que, posteriormente, serviu de base ideológica para a luta de libertação nacional dos países africanos".

O TEN capitalizava apoio dos setores mais democráticos do país, proporcionando maior reconhecimento e apoio. 0 recrutamento do grupo era eclético, sendo o público alvo operários, empregadas domésticas e pessoas de profissão não definida ou subjugada. Duas associações fizeram parte do grupo: A Associação das Empregadas Domésticas e o Conselho Nacional de Mulheres Negras. Uma das primeiras ações do TEN foi a alfabetização de seus integrantes, para que pudessem fazer a leitura dos textos teatrais. Dado a escassez de textos brasileiros que dessem conta da proposta do TEN, o espetáculo de estreia do grupo foi a montagem de 0 Imperador Jones, texto do dramaturgo norte-americano Eugene O'Neill. Além dos cursos oferecidos pelo Teatro Experimental do Negro, o grupo contava com o Jornal Quilombo, voz ativa na imprensa negra de São Paulo. 0 periódico era responsável por denunciar discriminações e apoiar organizações afro-brasileiras. Com a instauração da ditadura em 1964, o Teatro Experimental do Negro perde forças, sendo praticamente extinto em 1968, quando Abdias parte para o exilio nos Estados Unidos.

\section{PRIMEIRO ATO - CONSTRUCTO DA ARTE}

Para que seja possível articularmos as noções de saber e poder que podem ser tangenciadas nos ditos da obra dramatúrgica sobre o enunciado de um sujeito que se apresenta em "Sortilégio - Mistério Negro", concebemos, aqui, a noção da arte em Deleuze. Assim, tomamos a obra de arte como dispositivo de resistência frente à negação da negritude ou sua tomada sincrética até então evocada pelo chamado mito da democracia racial, e não como comunicadora de uma nova performance que viesse a propor a modificação de uma concepção anteriormente estabelecida: 
A obra de arte não é um instrumento de comunicação. A obra de arte não tem nada a ver com a comunicação. A obra de arte não contém, estritamente, a mínima informação. Em compensação, existe uma afinidade fundamental entre a obra de arte e o ato de resistência. Isto sim. Ela tem algo a ver com a informação e a comunicação a título de ato de resistência. (DELEUZE, 1999, p. 13)

Assim, o que aqui se coloca é o discurso como constituidor de uma forma estética ou concepção artística, características que, na mesma direção, constituem os campos de um discurso. Na medida em que, para Foucault (2009, p. 53), discurso trata-se de uma formação discursiva, como um conjunto de regras determinadas no tempo e no espaço que possibilitam as condições de exercício da função enunciativa, remonta-se o período no qual Nascimento compõe o texto teatral e a concepção de Movimento Negro articulada no Brasil. Tomamos, para inflexão analítica, a concepção da arte e da teatralidade de Abdias como dispositivo, isto é, um conjunto de formas históricas de agenciamento e de coerção do saber e do poder que atuam em um dado tempo e espaço e que se materializam de formas diversas, constituindo um campo discursivo nos processos de subjetivação.

\section{SEGUNDO ATO - SORTILÉGIO, UM MANIFESTO}

Entre os anos de 1950 e 1951, no auge da produção do TEN, Abdias do Nascimento escreve o espetáculo teatral Sortilégio - Mistério Negro. 0 enredo se passa durante a noite, num bosque no alto de um morro. $A$ atmosfera é mística e fluídica, incorporando elementos teatrais semelhantes aos conhecidos na tragédia grega, como o coro e o oráculo. Três filhas de santo, que ora são apresentadas como reais, ora como visões, terminam um despacho e enunciam:

- Obrigação cumprida. Serviço bem feito.

Exu, orixá africano, se aproxima, observa, circula brevemente o espaço e toma seu lugar de trás de uma gameleira. Em meio a axés, saravás, profecias, pontos (canções) à Ynhansã, lemanjá e Exu, anunciam a chegada de Emanuel, homem negro, advogado, que renuncia sua ancestralidade, cor e religião. Contudo, como elemento fundante da tragédia, não se pode renunciar ao destino.

Emanuel, protagonista, chega correndo e assustado. Foge da polícia. Acaba de cometer um crime, cujas características e motivações são desenroladas paulatinamente no decorrer da trama. Encontra no alto do morro um bom esconderijo, mas abomina o despacho e todos os elementos ritualísticos dispostos no espaço cênico. Aqui, começa seu discurso e conta sua história, narrada através do clamor de sua consciência e suas lembranças. Emanuel fora apaixonado por uma mulher negra chamada Efigênia, que sonhou ser bailarina, já que não podia frequentar os sambas de gafieira por conta do ódio de Emanuel à toda expressão afro. Efigênia, na tentativa desesperada de alcançar seu sonho, acaba tornando-se prostituta nas mãos daqueles de quem pensou que obteria favores em prol de sua carreira, que jamais acontecera. Emanuel, cego de dor, casa-se com Margarida, uma mulher branca que não o amava, mas que admitira o casamento para salvar sua honra e de sua família, já que não era mais virgem.

No desenrolar do enredo, Emanuel tem visões de Efigênia, Margarida e de entidades que formam o coro do espetáculo e o redirecionam no caminho de seu destino. Ele oscila entre sua descrença, seu catolicismo de família e sua matriz africana destinada pela cor, sendo a ambivalência entre seus desejos e vontades os elementos principais do texto. 0 protagonista bebe e fuma do despacho de Exu. Ao final do espetáculo, já embriagado, tomado pelo credo e para não cair nas mãos brancas da polícia, por quem já havia sido detido injustamente diversas vezes, vê em sua reverência aos orixás um ato de resistência. Descobre-se, então, que o crime de Emanuel foi assassinar Margarida, a mulher com a qual havia casado e que abortara um filho seu para que ele não nascesse negro. Com 
a lança de Exu, as três filhas de santo transpassam seu corpo, embriagado, de joelhos e entregue ao destino, e repetem o mesmo texto inicial. A oferenda está pronta. Cai o pano.

\section{TERCEIRO ATO - ALGUMAS CARACTERÍSTICAS DO PROCESSO}

Sobe o pano. Paulatinamente, um espaço se revela ao olhar. Não os fragmentos que compõem a imagem pelo subir da clássica cortina de veludo vermelho, nem os que com o acender das luzes revelam-se em jogos de luz e sombra. Mas um quadro. Uma imagem completa, uníssona em si e suas partes, que entrega um espaço, um tempo e um sujeito. Os corpos que tomam o tablado têm a cor de seus ritos. Movimentam-se sob as luzes como numa grande dança de apresentação.

As linhas de diálogo que compõem a carpintaria teatral denotam a vontade das personagens. Na ausência da narrativa romântica, todo o desenrolar de um enredo se dá na ação e na fala dos sujeitos criados pelo dramaturgo. 0 desejo destas criaturas se manifesta por suas próprias narrativas e, ainda que situado no campo ficcional, denotam do criador algo que lhe pertence. Conhecedor desta técnica de escrita dramatúrgica denominada de carpintaria teatral, persegue passos básicos de roteirização em busca do conflito cênico, permanecendo não refém de suas personagens e nem ditador de suas vontades, mas em constante relação intersubjetiva entre os dois espectros. Outra escrita, porém, que também compõe a obra dramatúrgica é a rubrica. Esta jamais será enunciada no palco. A rubrica possui a função de orientação do autor para os atores e suas criações. A quantidade de rubricas grifadas no texto e a rigidez com a qual são seguidas diz muito do período durante o qual ele foi produzido.

\footnotetext{
O fato de que as rubricas, cuja própria riqueza varia para mais ou para menos de acordo com as épocas e os autores, sejam ou não observadas de maneira rigorosa é uma questão de escolha cênica, mas não atinge a letra do texto. De modo geral, pode-se dizer que quanto mais um texto de teatro pertence ao cânon dos grandes clássicos, menos está exposto a sofrer mudanças causadas pela perspectiva a encenação. (GRÉSILLON, 1995, p. 272)
}

Através da rubrica, o encenador se localiza no palco, descobre a intencionalidade da ação, que elemento cênico ou adereço que precisa tomar para si, o que sente a personagem ao verbalizar o texto e até mesmo no que ela está pensando enquanto projeta sua voz. Este elemento não é outra coisa senão a vontade do autor. Protegida pelo pacto dramatúrgico, essa escrita, jamais pronunciada, jamais exposta àqueles que expectam, evoca o desejo do compositor cênico. Abdias não se traduz num dramaturgo econômico em tais esclarecimentos de ação, mas sim propõe sentimentos e vicissitudes ao intérprete ao longo de toda obra. Tal postura da linguagem empregada em sua dramaturgia é capaz de comunicar sua visão estética sobre a negritude e seu posicionamento político no Movimento Negro. Deleuze e Guattari (1995, p. 11), tratam da linguagem como mais comunicativa do que informativa, atribuindo a tal subjetivação propriamente linguística a explicação de tudo aquilo que fazemos existir ao dizê-“lo”.

\footnotetext{
Chamamos palavras de ordem não uma categoria particular de enunciados explícitos (por exemplo, no imperativo), mas a relação de qualquer palavra ou de qualquer enunciado com pressupostos implícitos, ou seja, com atos de fala que se realizam no enunciado, e que podem se realizar apenas nele. As palavras de ordem não remetem, então, somente aos comandos, mas a todos os atos que estão ligados aos enunciados por uma "obrigação social". Não existe enunciado que não apresente esse vínculo, direta ou indiretamente. Uma pergunta, uma promessa, são palavras de ordem. (1995, p. 12)
}

0 que se produz pelo enunciado das personagens de Sortilégio - Mistério Negro são também palavras de ordem que compuseram um imperativo do que era, ao menos para Abdias e para o TEN, ser sujeito negro no Brasil 
da década de cinquenta, e os efeitos da composição desta estética ainda ecoam no Movimento Negro. Observemos alguns recortes retirados do texto teatral:

Figura 1. Diálogo entre Filhas de Santo, p. 164.

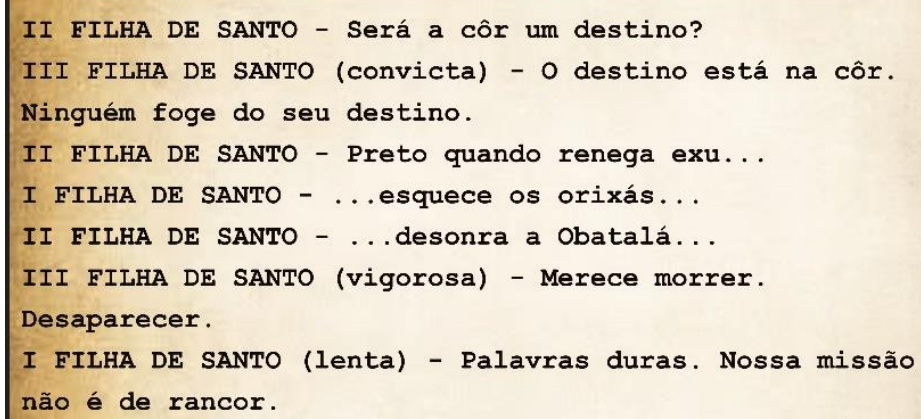

Figura 2. Diálogo entre Filhas de Santo, p. 164.

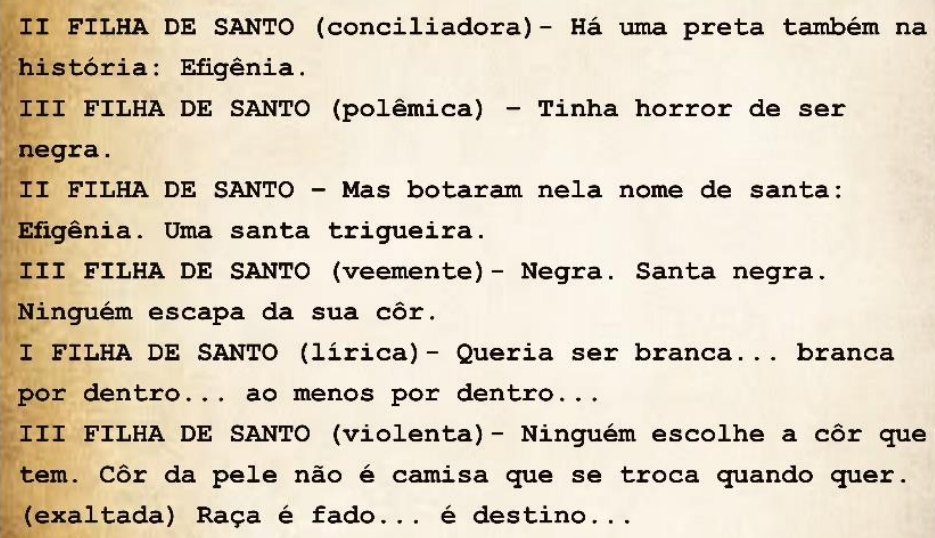

Os trechos acima foram retirados das cenas iniciais de Sortilégio. As Filhas de Santo apresentam-se, conforme já dito, como personagens invisíveis a Emanuel. De tal forma, não contracenam diretamente com o personagem, ocupando função similar ao coro nas tragédias gregas. Esta estrutura clássica do teatro grego atribuía ao coro trágico a expressão da voz do próprio Dionizio, que comunicava ao expectador que o destino traçado pelos deuses era inevitável, tornando o povo também coro a declarar a vontade dionisíaca.

No jogo ritualístico encontrado na tragédia grega, o espectador do teatro ático, enquanto povo, multidão, muralha, está sentado nas pedras do anfiteatro, disposto para a festa. Ele se dilui junto ao coro e é representado pelo herói trágico, na mais intensa representação. A tragédia grega leva para o palco a relação de poder entre a palavra e a música. 0 protagonista domina a palavra, mas é a música do coro que domina o que as palavras produzem. (PAULA JUNIOR, 2007, p. 137)

Partindo da hipótese de que a linguagem teatral construída por Abdias ao escrever Sortilégio - Mistério Negro remonta elementos da tragédia grega, observemos os diálogos entre as Filhas de Santo. Na figura 1, a Filha de Santo II questiona se seria a cor um destino, ao passo em que a personagem Filha de Santo III responde que o destino está na cor e que não há como fugir do destino. 0 diálogo segue. Duas das personagens declaram que negar Exu, esquecer os Orixás ou desonrar Obatalá é inadmissível e o negro que o faz merece desaparecer, mas logo são repreendidas pelo enunciado calmo (conforme rubrica) da Filha de Santo I. Abdias compõe sua obra 
comunicando seu posicionamento político. Negar a cor, segundo as personagens, é negar ancestralidade e a matriz afro.

Para o autor, a reaproximação aos corpos e cultura violentados e subjugados por séculos de escravidão, políticas de branqueamento e mitos como o da democracia racial, é o único mecanismo que pode fazer frente de resistência a cultura hegemônica. Para Nascimento (2016, p.47), somente a partir da experiência e situação no grupo étnico-cultural a que se pertence é que se pode surpreender a realidade que condiciona e define o sujeito.

As Filhas de Santo dialogam sobre Emanuel, o advogado protagonista e Efigênia, seu antigo amor. Ao referirem-se à Efigênia, demonstram repúdio por ela haver se envolvido com brancos para obter êxito em sua carreira artística.

As falas que sucedem a trama comunicam que não há fuga para a cor. Aliadas ao texto, as rubricas anunciam, antes de cada fala, a intenção do dramaturgo sobre cada uma das personagens: irônica; conciliadora; polêmica; veemente; lírica; violenta; excitada. As conexões das dimensões explícitas da obra, que serão verbalizadas pelos encenadores, e as intenções (implícitas) propostas por Nascimento, compõem um quadro/recorte de múltiplas comunicações de resistências e, por sua vez, dão vazão à uma ideia de ser sujeito negro.

Figura 3. Diálogo entre Emanuel e as visões de Efigênia e Margarida, p. 178.

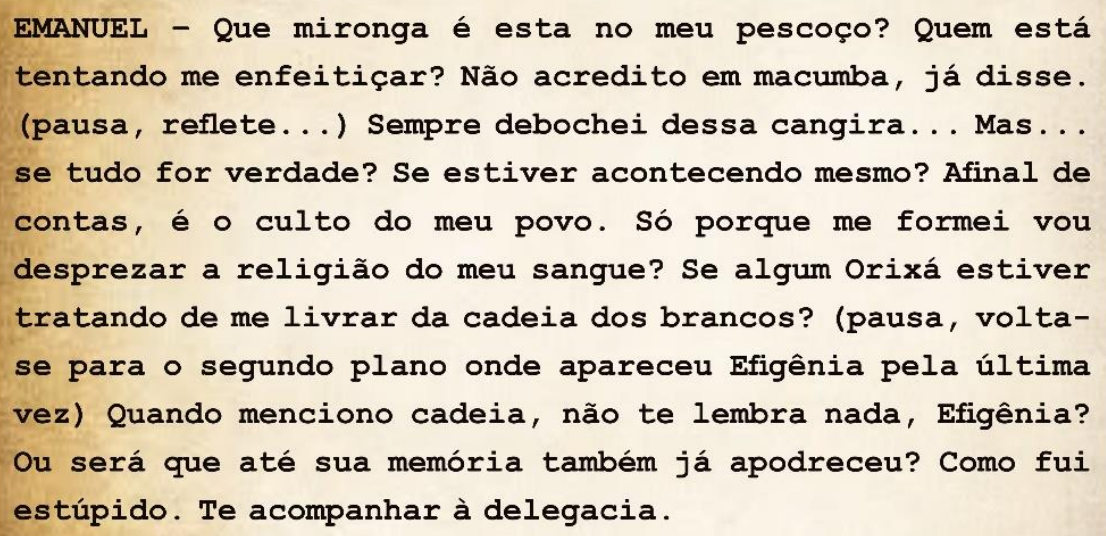

No trecho de cena acima, Emanuel encontra-se sugestionado pelo canto e pela dança das personagens místicas. Exu acaba de por em seu pescoço uma guia sagrada de lemanjá. Quando o protagonista desperta, arranca a guia, mas se põe a questionar sua insistente negação ao credo.

- Afinal de contas, é o culto do meu povo. Só porque me formei vou desprezar a religião do meu sangue?

Alguns apontamentos são possíveis com base neste texto. Emanuel, aos poucos, questiona se a graduação, o distanciamento do candomblé e o desprezo ao seu povo lhe tornou o homem livre que sonhou ser. Em seus monólogos, conclui que nem mesmo a faculdade, o casamento com uma mulher branca ou a devoção ao catolicismo foram suficientes para borrar a demarcação da cor de sua pele. Seu corpo, que outrora julgara liberto das correntes históricas de seus ancestrais, luta para sobreviver da polícia que lhe persegue, da exaustão que Ihe dilacera e da culpa, que Ihe corrói. Emanuel compreende que não há fuga possível. Para Foucault (1987) o poder, transita nas redes das relações, e mesmo quando há resistência, ali ele está. Não há, de fato, fuga para uma construção que não é objetal, mas sim uma prática. Logo, não há fuga para Emanuel, pois as relações de poder estarão presentes, seja na negação da Negritude ou na incorporação de tal constructo. Contudo, no exercício cênico, uma estratégia é possível. Para Simão e Sampaio (2018, p. 673), 
Se os corpos resultam de suas interações com outros corpos e com o meio, eles afetam as práticas de poder às quais estão submetidos. Por esse ângulo, são os corpos que (co)regulam, alimentam e mantém a colonialidade; logo, podem igualmente encontrar caminhos que evidenciem ou minimizem tal influência na criação e recriação da cultura em que se inserem em direção ao reconhecimento da colonialidade e, quem sabe, de percursos de descolonialidade.

Ao dar este tom à interpretação da obra de Nascimento, é possível considerar alguns elementos implícitos em sua obra e o tom político de sua leitura sobre as relações étnico-raciais. Em Sortilégio, o destino do homem negro é enegrecer-se e encontrar a estética da existência ao entregar-se de corpo e alma à Negritude. Fazer, para si, um corpo/arte, uma existência/arte. Fazer de sua vida uma obra, com valores estéticos e éticos. Este processo, encontrado como exercício nos povos greco-romanos, só era possível a partir da reflexão e do cuidado de si que, segundo Foucault (2004), preparava o homem para a vida política. Com a ferramenta das artes teatrais, talvez Abdias comunicasse a necessidade de certo conhecimento de si pela releitura da matriz impossibilitada violentamente e que, afastada pelo colonialismo, impossibilitou aos povos negros acessar a gênese de sua história.

\section{ALGUMAS CONSIDERAÇÕES}

Após trinta anos de censura pela radiodifusão francesa, a voz de Antonin Artaud (1947/1983, p. 161) ecoa pelas ruas de Paris: "Se quiserem, podem meter-me numa camisa de força, mas não existe coisa mais inútil que um órgão. Quando tiverem conseguido um corpo sem órgãos, então o terão liberado dos seus automatismos e devolvido sua verdadeira liberdade. “

A ideia de Corpo sem órgãos (CsO) aparece pela primeira vez através da transmissão radiofônica do poeta, dramaturgo e encenador francês, na peça radiofônica intitulada "Para Por um Fim no Juízo de Deus". Evocava um corpo livre de seus automatismos, pleno, intenso e vívido em seus movimentos desorganizados. Um corpo que, ao dar as costas ao martelo do juízo, apresenta-se despretensioso e disfuncional em suas programações, e possui a estética de um animal performático e erótico (p. 173). Gilles Deleuze e Félix Guattari tomam e trabalham com a ideia de Artaud para pensar a construção da singularidade na produção da máquina de guerra nômade em Mil Platôs. O CsO, contudo, não trata de um conceito. Para Deleuze e Guattari, "antes uma prática, um conjunto de práticas", (2012, p. 12), como um corpo da experiência em suas próprias forças, sempre no campo do devir e constituído no plano de imanência. Esta construção requer um devir esquizo para a reivindicação de uma existência livre, revolucionária, porque principia pelo fim dos automatismos. Não o esquizofrênico patológico, mas esquizo porque perde suas bordas, como o sujeito desterritorializado e descodificado. Contudo, há como constituir-se como sujeito no "fora" sem perder-se, sem experimentar-se? Tangenciar este CsO seria uma prática improvável? Para tocar o fora, faz-se necessário perder-se? Na obra de Abdias, Emanuel é um homem negro, advogado, que acaba de cometer um crime. Seu discurso apresenta a negação de todo retorno à uma matriz africana ou ancestralidade. Seu ódio a expressão afro é o elemento disfuncional de sua libertação. Ao reconectar-se com esta matriz, mas entregue as forças que Ihe cercam, Emanuel é liberto, enfim, de seus automatismos, pela lança de Exu que Ihe transpassa o corpo.

Anuncia-se, antes que se esqueça, que a obra de Abdias não está disponível aos prazeres de uma direção impiedosa. Ela possui um corpo, constitui-se como um corpo, grita como um corpo que agoniza. É, antes de tudo, um corpo sem órgãos. Vocifera como um corpo sem órgãos; e a única coisa que comunica é uma resistência. Ecoa, pelas fibras tensionadas de uma resistência, que o poder ali transita, nas ramificações de um rizoma, e evoca uma 
nova economia das relações de poder. Consiste "Em usar as formas de resistência contra as diferentes formas de poder como um ponto de partida." (Foucault, 1995, p. 234).

A proposição da estética da Negritude de Abdias não pode ser nomeada. 0 que se faz possível é tangenciar algumas hipóteses do que era, na leitura de Nascimento, o seu ideal de sujeito negro no Brasil. Sua escrita ficcional possibilita, além de flutuar entre elementos afro-brasileiros, o contato direto com a luta identitária na década de cinquenta.

\section{REFERÊNCIAS}

ARTAUD, A. Para acabar com o julgamento de Deus (1947). In: WILLER, C. (tradução, seleção e notas). Escritos de Antonin Artaud. Porto Alegre: L\&PM, 1983.

DELEUZE, Gilles. 0 ato de criação. Trad. José Marcos Macedo. Em: Folha de São Paulo, Caderno Mais, 27 de junho de 1999.

DELEUZE. Gilles; GUATTARI, Félix. Mil Platôs: capitalismo e esquizofrenia. v.1, São Paulo: Editora 34, 1995.

DELEUZE, Gilles; GUATTARI, Félix. Mil Platôs. São Paulo: Editora34, 1995. v. 2.

DOMINGUES, Petrônio. Movimento da Negritude: Uma breve reconstrução histórica. Mediações - Revista de Ciências Sociais, Londrina, v. 10, n 1, p. 25-40, 2005.

DOMINGUES, Petrônio. Movimento negro brasileiro: alguns apontamentos históricos. Tempo, Niterói, v. 12, n. 23, p. 100-122, 2007.

FOUCAULT, Michel. A Arqueologia do Saber. Rio de Janeiro: Forense Universitária, 2009.

A Hermenêutica do Sujeito. São Paulo: Martins Fontes, 2004.

Microfísica do Poder. Trad. Roberto Machado. 4 ed. Rio de Janeiro: Graal, 1984.

O sujeito e o poder. In: DREYFUS, Hubert L; RABINOW, Paul. Michel Foucault, uma trajetória filosófica: para além do estruturalismo e da hermenêutica. Rio de Janeiro: Forense Universitária, 1995. p. 231-251.

GRÉSILON, Almuth. Nos limites da Gênese: da escritura do texto de teatro à encenação. Estudos Avançados. v.9 n.23, São Paulo, 1995.

IPEAFRO, Seção TEN. Disponível em: <http://ipeafro.org.br/acoes/acervo-ipeafro/secao-ten/>. Acesso em 3 de 02 de 2019.

NASCIMENTO, Abdias do. Dramas para negros e prólogo para brancos. Rio de Janeiro: TEN, 1961

NASCIMENTO, Abdias do. O Genocídio do negro brasileiro. São Paulo: Perspectivas, 2016.

NASCIMENTO, Abdias do. O Quilombismo: documentos de uma militância pan-africanista. Petrópolis: Vozes, 1980.

PAULA JÚNIOR, Haroldo Osmar de. O Papelo do Coro na tragédia grega em Niezsche. Quinto Fórum de Pesquisa Científica em Arte, Paraná, p.130-138, 2007. Anual.

SIMAO, Marina Fazzio; SAMPAIO, Juliano Casimiro de Camargo. Corpo e Descolonialidade em Composição Poética Cênica. Rev. Bras. Estud. Presença, Porto Alegre, v. 8, n. 4, p. 665-690, dez. 2018. 